\title{
Estudio de los procesos de recepción de la audiencia de la "Radio Cadena en Lengua Maya"
}

Inés Cornejo Portugal ${ }^{1}$

\begin{abstract}
En el itinerario desplegado por la teoría de la comunicación crítica latinoamericana en los últimos treinta años se observa un cambio sustantivo. De considerar al receptor como "pasivo ejecutante" de las propuestas hegemónicas de los medios de comunicación, se le rehabilitó como sujeto social con capacidad propositiva y de respuesta frente a las ofertas culturales de los mismos. Como resultado de lo anterior, el quehacer académico del campo de la comunicación en los años noventa se enriquece y consolida para dar cabida a un esquema explicativo más complejo que permite integrar el análisis del receptor/consumidor en dinámicas socioculturales donde el estudio de las "mediaciones" (Barbero, 1989) y la "hibridación cultural" (García Canclini, 1990) le dan sentido.
\end{abstract}

Es así que nuevos desafíos nos interpelan para acercarnos a la experiencia radiofónica que difunde y transmite mensajes a través de alguna de las lenguas indígenas; ya no es posible desplazar, sin una problematización rigurosa, los hallazgos teóricos y empíricos del estudio y la investigación sobre la radio en zonas urbanas o citadinas, sea ésta comercial, comunitaria, universitaria, cultural o "pirata". Hoy en día, son necesarios innovadores instrumentos y categorías analíticas para dar cuenta de aquellas propuestas radiofónicas que desde emisoras promovidas por el Estado mexicano, producen, recrean y difunden el acervo cultural indígena.

Ese es el sentido de la información empírica que a continuación se entrega, dicha información no hace sino demostrar cómo el indígena ha dejado de ser un punto de partida desde el cual se mide el "atraso" o el "progreso" de determinada sociedad. Asimismo, los gustos, preferencias y demandas musicales mencionados por la población entrevistada nos revelan ciertas mixturas entre acervos culturales (indígena y mestizo) que hasta pocas décadas eran considerados como externos o excluyentes.

1. Docente-investigadora, Departamento de Comunicación, Universidad Iberoamericana, México. 
El presente documento está integrado por los siguientes apartados: en el primer capitulo se presentan la perspectiva teórica y metodológica que condujo nuestra investigación, se describen las guías de investigación, objetivos, categorías, muestra y cuestionario, y se realiza una breve recapitulación en torno al trabajo de campo llevado a cabo en cuarenta municipios del estado de Yucatán y su capital Mérida, para conocer los procesos de recepción de la audiencia del espacio denominado "Radio Cadena en Lengua Maya".

La cronología básica y el proyecto radiofónico de la "Radio Cadena...", así como su programación, constituyen el segundo capítulo. En el tercero, se analizan las particularidades de la comunidad receptora que se encuentra bajo la cobertura de Radio Solidaridad, por ende, de "Radio Cadena...", tomando en cuenta el equipamiento cultural doméstico con el que se cuenta en los hogares, los hábitos de recepción radiofónica de los entrevistados, las representaciones que poseen frente a la lengua maya, además de datos vinculados con el resto de las emisoras que conforman sus preferencias e integran la competencia en el cuadrante.

En el cuarto apartado, se interpreta la información relacionada con los radioescuchas habituales de la "Radio Cadena...", examinando su nivel de "escucha", así como las preferencias y discrepancias de la audiencia relacionadas con dicha oferta radiofónica. Por último, en el quinto capítulo, se esbozan las conclusiones más sobresalientes con base en la evidencia empírica recabada.

El espacio radiofónico "Radio Cadena en Lengua Maya" comenzó sus transmisiones hace apenas tres años, en junio de 1997. En la presente investigación encontramos que 30 por ciento de los radioescuchas, bajo la cobertura de Radio Solidaridad, que poseen al menos un aparato de radio y que lo sintonizan de manera cotidiana, dijeron haber escuchado alguna vez uno de los tres programas que conforman dicha barra. Como se argumentará en las líneas siguientes, conjeturamos que el nivel de "escucha" que alcanza "Radio Cadena..." resulta promisorio si consideramos el breve periodo que posee dentro del cuadrante.

Finalmente se debe extender un profundo reconocimiento y agradecimiento a quienes, de una u otra manera, formaron parte de este trabajo; sin ellos hubiera sido imposible llevar adelante esta desafiante tarea.

Al Delegado Estatal del Instituto Nacional Indigenista (INI) en Mérida-Yucatán, Arturo Caballero Barrón, el interés y la motivación constante para seguir profundizando en el estudio de esta experiencia radiofónica cuya población beneficiaria son los indígenas mayas.

A los trabajadores y voluntarios de la Delegación del INI en Yucatán y de "La Voz de los Mayas" (XEPET), Peto, que estuvieron a cargo del registro y la elaboración 
rigurosa de los datos empíricos de la comunidad receptora entrevistada: Lidia $\mathrm{Ku}$ Puch, Emilio Ku Puch, Alicia María Ruiz Mena, Filemón Ku Che, Santiago Gutiérrez, Catalino Orilla, Luis Cambranis, Luis Felipe Tapia, Fredy Armando Chin Cen, Marcos Keb Canich, Dianela Marin Perera y Lorenza Balam López.

Al Director de la Radio de XEPET, Víctor Canto, quien diseñó minuciosa, paciente y detalladamente las rutas para realizar el trabajo de campo.

A la investigadora adjunta de esta propuesta, Elizabeth Bellon, por su interlocución acertiva y permanentes aportes durante la realización del trabajo de campo así como en el desarrollo del presente documento.

\section{Aproximación teórica y metodológica}

La relación entre la radio y la audiencia puede ser percibida por los radioescuchas desde dos niveles: $a$ ) como "telón de fondo" y $b$ ) como "interlocutora". En el primer caso, cuando el receptor escucha la radio como actividad común, incluida en sus prácticas cotidianas, su presencia es marginal y constituye el "telón" del escenario familiar; en el segundo, el medio capta a una audiencia específica y logra hacerla partícipe del proceso comunicativo, convirtiéndose en "interlocutora", y su presencia tiende a ser esencial.

Al parecer, las emisoras indigenistas o aquellos espacios radiofónicos que difunden mensajes en alguna de las lenguas indígenas podrían estar asumiendo la función de "interlocutoras", en la medida en que interpelan al radioescucha con transmisiones estructuradas a partir de aspectos que identifican y sirven a la etnia: la lengua, la música y los avisos. Cuando la emisora indigenista "les habla su lengua, pasa su música y les dice lo que sucede con sus familiares y su pueblo", se convierte en un medio que la comunidad asume como propio; es posible identificarse y reconocerse en él porque expresa y recrea su cultura.

Por ello, el medio radiofónico en el ámbito rural confirma sus posibilidades como fuente de información y entretenimiento pero, sobre todo, como un medio "cercano" y "apropiable". "Cercano" en la medida que difunde los valores de la cultura indígena, "apropiable" porque la audiencia siente que puede participar de acuerdo con sus expectativas e intereses, por ejemplo, llevando una canción, un cuento o un aviso.

En junio de 1997 se celebró un convenio entre el Instituto Mexicano de la Radio (IMER) y el Instituto Nacional Indigenista (INI), con el propósito de operar de manera integrada diversas estaciones radiodifusoras del Poder Ejecutivo Federal, entre las que se encuentra Radio Solidaridad. Se trataba de comunicar a las comunidades 
mayas entre sí y con el resto de la sociedad por medio de programas que dieran a conocer su cultura. Fue de esta manera como se organiza y difunde la barra programática denominada "Radio Cadena en Lengua Maya", a través de las ondas hertzianas de Radio Solidaridad.

A poco más de tres años de iniciada su transmisión, es imprescindible contar con datos recientes que nos aproximen a los hábitos, preferencias, demandas y expectativas de los radioescuchas de la "Radio Cadena...", con el afán de adecuar la oferta radiofónica a las necesidades actuales de la población indígena maya.

La presente investigación fue del tipo analítico descriptivo. El objetivo general fue detectar y sistematizar los procesos de recepción de las colectividades indígenas frente a "Radio Cadena en Lengua Maya". Para ello se recurrió a la metodología e instrumentos cuantitativos ya que, en esta etapa del trabajo, interesaba mensurar el fenómeno comunicativo y esbozar posibles ejes de acción. El acercamiento cuantitativo se realizó a partir de la aplicación de un cuestionario en una muestra probabilística en el área de cobertura de Radio Solidaridad.

\section{Guía de investigación}

La transmisión radiofónica de "Radio Cadena en Lengua Maya" interpela y convoca al auditorio en la medida en que expresa y recrea algunos de los parámetros culturales (música, lengua, creencias) de los receptores indígenas mayas.

\section{Objetivo general}

Revelar las diferentes prácticas de recepción de los indígenas frente a "Radio Cadena en Lengua Maya", analizando las formas de exposición, demandas y expectativas frente a esta propuesta radiofónica.

\section{Objetivos específicos}

1. Conocer la significación de la propuesta radiofónica "Radio Cadena..." en la vida cotidiana indígena, en el "tiempo libre" y en la familia.

2. Explorar los usos y apropiaciones más comunes atribuidos a dicha propuesta: por sexo (masculino y femenino), por generación (grupos de jóvenes y adultos) y por lengua (monolingüe castellano, monolingüe indígena y bilingüe). 


\section{Propuestas de categorización}

Para cumplir el objetivo de esta investigación fue necesario explorar y profundizar en los procesos de recepción radiofónica de los radioescuchas; para ello se seleccionaron dos categorías de análisis:

A. Usos de "Radio Cadena..." y modos de escucharla

- Escucha todo el día Radio Solidaridad o lo hace selectivamente atendiendo a la propuesta de "Radio Cadena".

- Quién toma la decisión de escuchar "Radio Cadena".

- Con quién escucha "Radio Cadena".

- Demandas y expectativas que se formulan a "Radio Cadena".

- Razones por las que escucha "Radio Cadena".

- Razones por las que no escucha "Radio Cadena".

- Compite "Radio Cadena" con programas de otras estaciones o con otros medios de comunicación.

- Usos que se le atribuye por generación (jóvenes y adultos), por sexo (masculino y femenino) y por lengua (monolingüismo o bilingüismo).

- Diferentes formas o expectativas de participación en "Radio Cadena".

B. Funciones que se le atribuye a "Radio Cadena"

- Fuente de información.

- Fuente de entretenimiento.

- Función educativa (consejos y orientación).

- La programación como instancia de recreación cultural (música producida local y regionalmente, transmisión en lengua indígena, difusión de cuentos y leyendas).

\section{La muestra}

El diseño de la muestra se basó en cálculos estadísticos según el método de proporciones, con un rango de error de \pm 5 por ciento y de acuerdo con los datos de "El Conteo de 1995. Población y Vivienda. Resultados Definitivos. Tabulados Básicos. 
Instituto Nacional de Estadística, Geografía e Informática (1977)". Yucatán (Tomo II). Para seleccionar la muestra se utilizó la fórmula siguiente:

$$
\begin{aligned}
& \mathbf{N}=\frac{\mathrm{N}}{1+\mathrm{N}(\mathrm{e}) 2} \\
& \mathbf{N}=\frac{279336}{1+279336(0.05) 2} \\
& \mathbf{N}=\frac{279336}{699.34} \\
& \mathbf{N}=\quad 399.4
\end{aligned}
$$

Se aplicaron 440 cuestionarios con el afán de resguardar la información recuperada y discriminar las formas insuficientes, inconsistentes o incompletas. Para el análisis final se tomaron en cuenta 430 cuestionarios.

Nuestra población encuestada posee las siguientes características: 53 por ciento son mujeres y 47 por ciento hombres; de los cuales, 36 por ciento son jóvenes de 15 a 24 años, 20 por ciento son jóvenes adultos de 25 a 34,17 por ciento son adultos de 35 a 44 y 26 por ciento son adultos mayores de 45 años de edad.

El grado de escolaridad que prevalece entre nuestros encuestados es el de primaria (42 por ciento), seguido por el de secundaria (20 por ciento), sabe leer y escribir (13 por ciento), analfabeta ( 9 por ciento), preparatoria ( 8 por ciento), carrera técnica ( 5 por ciento) y estudios superiores ( 3 por ciento).

Las ocupaciones más frecuentes son las de ama de casa (31 por ciento), campesino (15 por ciento), empleado (13 por ciento), comerciante ( 9 por ciento), estudiante ( 8 por ciento), albañil ( 7 por ciento), estudiante y trabajador ( 4 por ciento), costurera (4 por ciento), mecánico ( 2 por ciento) y maestro (1 por ciento).

La mayor parte de los encuestados son bilingües (61 por ciento), aunque también se encontraron monolingües castellano ( 34 por ciento) y monolingües indígenas ( 5 por ciento). ${ }^{2}$

2. En términos generales, consideramos que la muestra resultante refleja los datos estadísticos reportados por los Censos Generales de Población y Vivienda 1995 y 2000, del Instituto Nacional de Estadística, Geografia e Informática (INEGI), México (cfr:www.inegi.gob.mx). Sin embargo, cabe precisar que al diseñar las rutas de campo se buscó de manera intencionada aquellas poblaciones en donde predominaran hablantes de lengua indigena, fueran monolingües o bilingües. 


\section{El cuestionario}

El instrumento de investigación fue una encuesta con preguntas de opción múltiple, en la mayoría de los casos, y de aplicación directa y personal de parte del entrevistador. La entrevista se efectuó mediante un cuestionario de tipo "recordación espontánea" (mención que hace el entrevistado sin ningún tipo de ayuda de parte del entrevistador).

Para elaborar un cuestionario adecuado a la investigación, se remitió un instrumento piloto al personal de la Delegación Estatal del INI en Yucatán, con el propósito de detectar el grado de comprensión de las preguntas y el rango de amplitud de las respuestas (primera prueba piloto).

Después, con los resultados de esta exploración, se diseñó el cuestionario que incluía preguntas abiertas y cerradas, el cual se aplicó en la Ciudad de Mérida a entrevistados monolingües castellano e indígena y bilingües (segunda prueba piloto). Finalmente, se eliminaron las preguntas confusas y se reformularon otras para precisar el instrumento definitivo.

Trabajo de campo

La investigación se llevó a cabo en cuarenta poblaciones del estado de Yucatán -incluyendo su capital, Mérida, donde se visitaron catorce colonias_-, durante la segunda quincena del mes de febrero de 1999. Para cumplir de manera cabal con nuestros objetivos, se impartió un curso de capacitación a doce trabajadores y voluntarios de la Delegación del INI en Yucatán, así como de "La Voz de los Mayas" (XEPET), ${ }^{3}$ todos bilingües, quienes estuvieron a cargo del levantamiento de la encuesta.

Este curso se dividió en dos etapas: en la primera, se reflexionó en torno a los principios básicos del encuestador; en la segunda, se analizó el cuestionario y se ensayó su aplicación.

De acuerdo con las pesquisas del director de la XEPET, se organizaron cuatro rutas de trabajo a cargo de doce entrevistadores y bajo la supervisión de tres jefes de campo.

3. "La Voz de los Mayas" (XEPET), sexta radiodifusora cultural indigenista en el país, instalada en el municipio de Peto, Yucatán, el 29 de noviembre de 1982, produce los programas que se transmiten en la "Radio Cadena en Lengua Maya" a través de Radio Solidaridad. 


\section{Rutas de trabajo}

Ruta 1 ( 32 por ciento):

Mérida, Cancel, Cholul, San Haroldo, Mulchechén I, Mulchechén II, Chichen Itzá, Plan de Ayala I, Plan de Ayala II, Los Reyes, Emiliano Zapata, San Antonio Xluch, Tecoh, Santa Rosa y Cecilio Chí (se consideraron aquellas colonias con alta densidad de población maya).

Ruta 2 (19 por ciento):

Umán, Samahil, Kinchil, Tetiz, Chocholá, Kopomá, Maxcanú, Halachó, Opichén, Muna, Santa Elena, Sacalúm, Abalá.

Ruta 3 (21 por ciento):

Timucuy, Tecoh, Acanceh, Seyé, Tahmek, Hocabá, Hoctún, Xocchel, Bokobá, Tekantó, Teya, Tepakán, Izamal, Tunkás, Quintana Roo, Dzitás, Uaymá.

Ruta 4 (28 por ciento):

Valladolid, Chichimilá, Tixcacalcupul, Chemax, Temonzón, Calotmul, Tizimín, Sucilá, Espita. ${ }^{4}$

\section{Antecedentes sobre "Radio Cadena en Lengua Maya"}

Cronología básica y proyecto radiofónico

En junio de 1997 se celebró un convenio de colaboración entre el Instituto Mexicano de la Radio (IMER) y el Instituto Nacional Indigenista (INI), el cual pretende hacer realidad uno de los propósitos de la acción radiofónica indigenista: que las comunidades mayas utilicen las emisoras operadas por el INI en Yucatán, o con aquellas radiodifusoras con las que se hayan firmado convenios, para comunicarse entre sí y con el resto de la sociedad.

Mediante la acción coordinada del INI y el IMER en el área de radiodifusión, se pretende contribuir a la preservación del patrimonio cultural indígena de México y a

4. Dado que en esta investigación interesaba conocer los procesos de recepción de la audiencia de la "Radio Cadena en Lengua Maya" para adecuar la oferta radiofónica a las necesidades de la población indigena maya, se seleccionaron las poblaciones de hablantes de lengua maya que estaban bajo el área de cobertura de la emisora. 
la difusión de la lengua maya. Por ello, se han implementado actividades de investigación, asesoría, producción y difusión, entre las cuales se encuentra la barra programática denominada "Radio Cadena en Lengua Maya".

La "Radio Cadena..." tiene a su cargo hoy día la producción y difusión de mensajes radiofónicos que difundan la cultura maya además de mensajes institucionales, en donde los indígenas mayas son el público receptor más importante con el que se desea establecer comunicación. Entre los programas que en febrero de 1999 contemplaba este espacio radiofónico se encontraban "El duende maya" (Arux K'at), "El despertar de los mayas" (U Yahal Mayao'ob) y "Nuestra vida" (K-Kuxtalil).

Gracias al convenio firmado entre el INI y el IMER, este proyecto radiofónico encontró un espacio en la XHYUC, Radio Solidaridad, emisora permisionada la cual es operada por el IMER. La XHYUC transmite las 24 horas del día por el 92.9 de FM, con una potencia de $30 \mathrm{Kw}$ (transmisor) y $100 \mathrm{Kw}$ (radiada), y se ubica en la ciudad de Mérida, Yucatán. El 26 de octubre de 1990 inició sus operaciones y a partir del 5 de enero de 1991 comenzó a transmitir las 24 horas del día.

\section{Barra programática}

La cobertura de Radio Solidaridad abarca 25 mil 482 kilómetros durante el día y 30 mil 664 por las noches, alcanzando territorio de los estados de Yucatán, Quintana Roo y Campeche. Su audiencia potencial de radioescuchas mayores de 15 años es de 975 mil 598 personas durante el día y un millón 16 mil 556 por la noche. Su perfil programático es 73 por ciento musical y 27 por ciento contempla programas informativos ( 14 por ciento), de difusión cultural (4 por ciento), de servicio (4 por ciento) e infantiles ( 4 por ciento).

Los programas "El duende maya" (Arux K'at), "El despertar de los mayas" (U Yahal Mayao'ob) y "Nuestra vida” (K-Kuxtalil), constituyen la barra radiofónica "Radio Cadena en Lengua Maya", la cual se transmite de lunes a domingo, de 5:00 a 5:30 a través de las ondas hertzianas de Radio Solidaridad. Cabe mencionar que esta radiodifusora clasifica dichos programas dentro del género de "servicio".

"El duende maya"(Arux K'at) se transmite los días lunes, miércoles y viernes dentro de esta barra y es producido por "La Voz de los Mayas", XEPET, emisora cultural indigenista del INI. Difunde consejos prácticos para la siembra y el cultivo utilizando como recurso el diálogo ficticio entre un duende y un niño maya. Es conducido en lengua maya por el locutor Bernardo Caamal y aborda asuntos tales como: desarrollo sustentable, agricultura de traspatio y cultura maya. 
"El despertar de los mayas" (U Yahal Mayao'ob), radiorevista cultural que se transmite en lengua maya los martes, jueves y sábados por el locutor Santiago Gutiérrez, tiene como objetivo difundir la lengua y tradiciones mayas a través de música autóctona, temas ecológicos, salud y derechos indígenas, entre otros. Se produce en coordinación con el inI y el Instituto de Cultura del Estado de Yucatán (ICY). Incluye información sobre mercados regionales, derechos indígenas y cultura.

"Nuestra vida" (K-Kuxtalil) se transmite los domingos y tiene como propósito hacer un análisis acerca de las condiciones actuales de la mujer, en especial de las indígenas, para contribuir a la solución de su problemática. Este programa es transmitido en maya y español por la locutora Ligia Marín, y se produce en coordinación con XEPET, "La Voz de los Mayas". 5

\section{Análisis de la comunidad receptora} de la "Radio Cadena en Lengua Maya"

Equipamiento cultural doméstico

De la muestra total entrevistada, únicamente 7 por ciento carece de aparato de radio al interior de sus hogares (Gráfica 1).

\section{GRÁFICA 1 \\ Tiene radio}

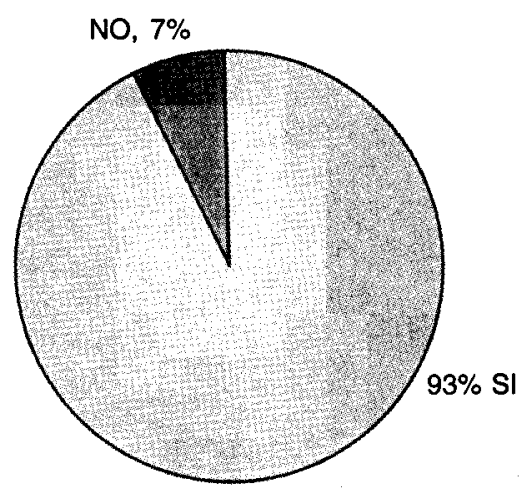

5. En octubre de 2000 la "Radio Cadena..." continúa sus tranmisiones sin cambios relevantes, salvo pequeñas modificaciones en su programación (Fuente: Víctor Canto, Director de XEPET, 2000). 
La radiograbadora ( 73 por ciento) y el estéreo ( 16 por ciento) forman parte del equipamiento cultural doméstico de nuestros encuestados quienes, en su mayoría, cuentan con un sólo aparato radiofónico (81 por ciento).

Aunque en menor medida, la televisión también está presente en casa de los encuestados (87 por ciento), contabilizando en su mayoría un sólo aparato televisor (82 por ciento).

La lectura de periódicos forma parte de la vida cotidiana de poco más de la mitad de nuestros entrevistados (58 por ciento), quienes manifestaron leer el Diario de Yucatán (56 por ciento), Por Esto (31 por ciento), Novedades (6 por ciento) y El Diario del Sureste (5 por ciento).

No obstante, estos datos habría que confrontarlos con observaciones posteriores puesto que nuestros informantes señalaron que la "lectoría" de periódicos es una práctica compartida; es decir, la adquisición de algún ejemplar no representa una toma de decisión por parte de los entrevistados, más bien, cuando algún miembro de la comunidad compra el periódico, éste suele pasar de mano en mano.

\section{Hábitos de recepción radiofónica}

Aunque las actividades favoritas por los encuestados durante su tiempo libre consisten en ver televisión (14 por ciento), descansar o dormir (13 por ciento) y trabajar (12 por ciento), escuchar radio (11 por ciento) aparece como la cuarta mención respecto a las actividades realizadas después del trabajo, las labores domésticas o el estudio, seguida de "costurar" o urdir hamacas (9 por ciento), la práctica de algún deporte como el fútbol ( 7 por ciento) o la lectura de diarios ( 7 por ciento).

Casi la totalidad de los encuestados dijeron escuchar radio (90 por ciento), ya sea más de tres horas al día ( 32 por ciento), una hora al día (20 por ciento), dos horas al día (17 por ciento), tres horas al día (14 por ciento), menos de una hora diaria (10 por ciento), o bien, todo el día (6 por ciento). Aquellos que no escuchan radio (10 por ciento) refieren que "no les gusta", "no tienen tiempo" o "no tienen radio" (ver Gráficas 2 y 3).

Se destaca que la primera mención por parte del segmento femenino respecto de las horas al día en las que escucha radio es la de más de tres horas (20 por ciento), mientras que el segmento masculino sintoniza el cuadrante sólo una hora al día (13 por ciento), seguido muy de cerca por la mención más de tres horas (12 por ciento). Dadas las condiciones de vida prevalecientes en el área estudiada, las mujeres parecen estar más apegadas a la radio por su permanencia al interior del hogar. 
De acuerdo con la variable edad, los datos muestran que los mayores de 45 años escuchan la radio ligeramente menos horas al día que el resto de la población encuestada. Así, los entrévistados de ese segmento etario optan por escuchar la radio una hora al día (6 por ciento) mientras que el resto de la muestra lo hace preferentemente más de tres horas al día.

\section{GRÁFICA 2}

\section{Escucha radio}

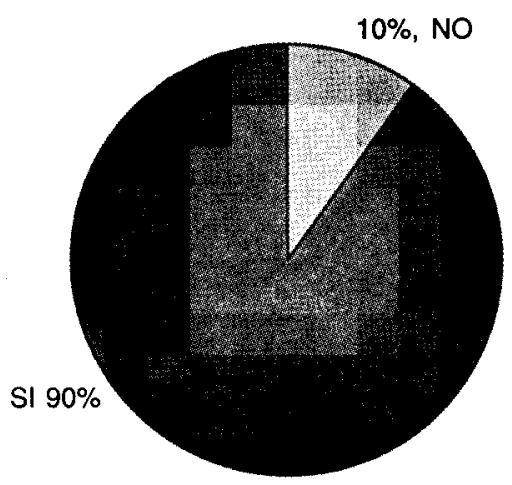

GRÁFICA 3.

Número de horas al día que escucha radio

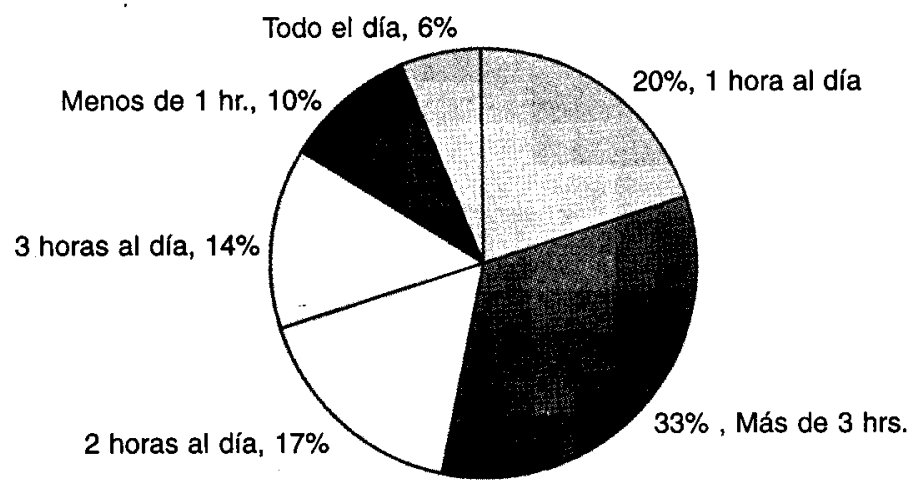


Respecto a la variable lengua, tanto los bilingües como los monolingües indígenas y castellano coinciden en escuchar la radio más de tres horas diarias; sin embargo, los monolingües indígenas y bilingües reportaron escucharla también durante una hora al día, a diferencia de los monolingües castellano quienes además la oyen más de tres horas al día. Si bien, el total de los entrevistados coinciden en el periodo que contempla la escucha radiofónica durante más de tres horas diarias, son los monolingües castellano quienes reportan un hábito más prolongado.

Los horarios favoritos para escuchar radio son de 12:00 a16:00 horas (21 por ciento) o a cualquier hora del día ( 21 por ciento), seguido de la.preferencia por el horario de 6:00 a 11:00 (18 por ciento) y la escucha durante todo el día (14 por ciento). La preferencia por el horario de 5:00 a 6:00 de la mañana, momento en que se transmite la programación de la "Radio Cadena..." aparece como la quinta mención (11 por ciento). Posteriormente, se citaron los horarios de 17:00 a 21:00 (9 por ciento) o de 21:00 en adelante (6 por ciento) (Gráfica 4).

\section{GRÁFICA 4}

Horario preferido para escuchar radio

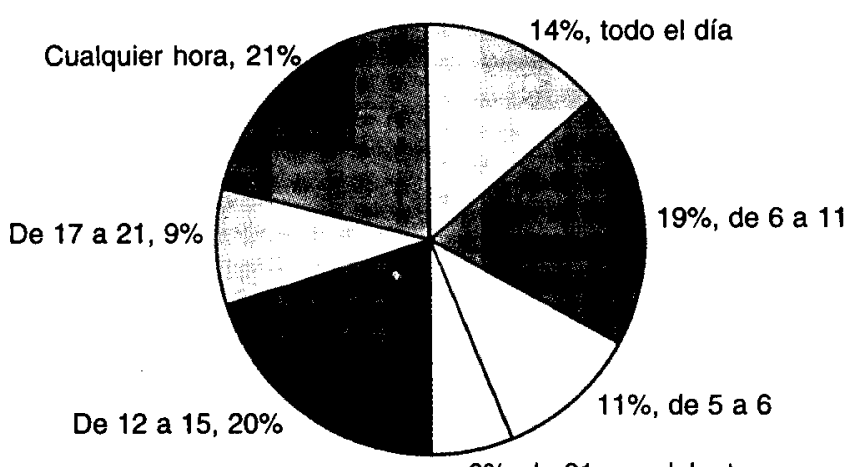

$6 \%$, de 21 en adelante

En términos de la variable sexo, el comportamiento de la muestra femenina, principalmente vinculado con las mujeres jóvenes, revela que la escucha radiofónica se da a cualquier hora del día (12 por ciento) así como en el horario de 6:00 a 11:00 horas (11 por ciento). Los hombres reportaron un comportamiento similar ya que también escuchan radio de 12:00 a 16:00 (11 por ciento), a cualquier hora del día ( 8 
por ciento) y de 6:00 a 11:00 (7 por ciento). Al parecer, la escucha de las mujeres ocurre durante la mañana o a lo largo del día, mientras que los hombres lo hacen por las mañanas, por las tardes $\mathrm{y}$, también, a cualquier hora del día.

La mayor parte de los encuestados carecen de un día preferido para escuchar la radio ya que 61 por ciento, sean hombres o mujeres, sin importar rango de edad o si se trata de hablantes de español o maya, respondió que les gustaba encender su aparato todos los días de la semana, además de que 10 por ciento dijo que cualquier día era bueno. Sobresale que los fines de semana (19 por ciento), es decir, sábado (4 por ciento), domingo (10 por ciento), y sábado y domingo mencionados de manera conjunta ( 5 por ciento), son los únicos días mencionados por los entrevistados de manera precisa y representativa.

La recepción radiofónica sigue siendo una práctica compartida puesto que más de la mitad de los entrevistados confesó escuchar la radio en compañía de sus familiares (68 por ciento), con los compañeros de trabajo ( 3 por ciento), familiares y amigos ( 2 por ciento) y amigos (1 por ciento). Sin embargo, se constata también que dicha práctica puede darse de manera solitaria (26 por ciento), tal como los datos nos lo señalaron en la investigación realizada en "La Voz de los Mayas"." Cabe destacar que del total de los entrevistados que dijeron escuchar la radio en solitario, son los jóvenes de 15 a 24 años bilingües o monolingües castellano, tanto hombres como mujeres, quienes suelen hacerlo en mayor medida ( 50 por ciento).

En este sentido, la casa es el espacio por excelencia de la escucha radiofónica ( 89 por ciento), además del lugar de trabajo ( 5 por ciento) o el negocio particular ( 2 por ciento). Pese a ello, todavía hay quienes suelen escuchar la radio en casa de algún familiar ( 0.8 por ciento) o en el campo ( 0.5 por ciento). De acuerdo con esta información, se aprecia una transformación en los hábitos de recepción de los radioescuchas en zonas indígenas ya que anteriormente se privilegiaba la casa de un familiar como lugar de reunión de los radioescuchas.

$\mathrm{Al}$ interior de los muros del hogar, el aparato radiofónico se instala en el espacio denominado "casa-principal" — - estancia que constituye la morada familiar en su conjunto-, de forma ovalada, con techos de palma y ubicada en el límite del terreno (83 por ciento). Dadas las características físicas y distribución de las viviendas, hay quienes también acomodan su aparato en el dormitorio ( 8 por ciento), en la cocina (4 por ciento) o en el corredor (3 por ciento).

El compartir la información difundida a través de los programas radiofónicos es una práctica cotidiana entre los encuestados ( 72 por ciento), ya que sólo 28 por

6. Véase "Estudio de la recepción de la radiodifusora cultural indigenista La Voz de los Mayas, XEPET. Peto, Yucatán". (1998, en prensa). En esta investigación 14 por ciento de los entrevistados manifestó escuchar radio en "solitario". 
ciento dijeron no conversar con otras personas en tomo a los contenidos de los programas. Los familiares ( 73 por ciento), amigos (19 por ciento), compañeros de trabajo ( 4 por ciento), vecinos ( 3 por ciento) y clientes ( 1 por ciento) son las personas con las que se intercambian apreciaciones sobre la transmisión radiofónica.

La selección de la emisora a escuchar por los integrantes de la familia no recae, como solía pensarse, de manera exclusiva en la figura paterna; es decir, según las respuestas de los entrevistados la "autoridad" del padre no determina la elección de la estación de radio a escuchar. Por el contrario, tanto los hijos ( 28 por ciento), el esposo ( 25 por ciento) y la esposa ( 24 por ciento) comparten esta decisión.

Representaciones frente a la lengua maya

Casi la totalidad de nuestros encuestados están de acuerdo con que sus hijos, primos, sobrinos u otros parientes hablen la lengua maya (98 por ciento) pues les "sirve para comunicarse", "para que no se pierda la lengua maya", "porque es nuestro origen, tradición y cultura", "para no perder nuestras raíces, tradiciones y cultura", "para aprender a hablarlo", "porque les gusta y es bonito", "porque en su familia algún miembro habla maya", "porque somos yucatecos", o bien, "porque lo exigen en la escuela", "porque vivimos en una región maya" o "porque es necesario para trabajar" (Gráfica 5).

\section{GRÁFICA 5}

De acuerdo en que sus familiares hablen lengua maya

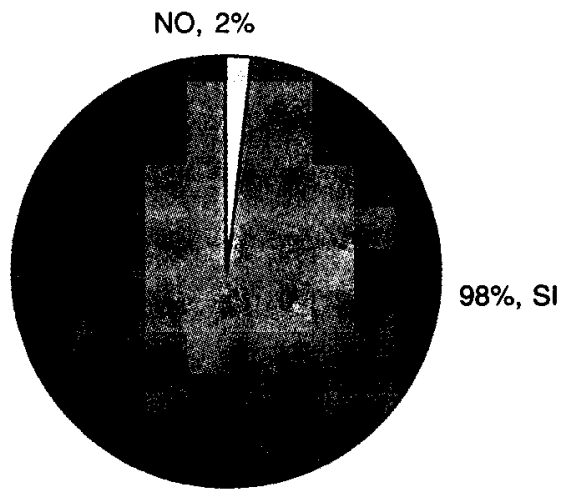

Los pocos entrevistados que expresaron su desacuerdo en torno a que personas cercanas hablen la lengua maya ( 3 por ciento), argumentaron que "no les gusta", 
"no la entienden", "los niños se confunden en la escuela", "no se pueden comunicar con gente que habla español", "no ganamos nada" o "no les dan trabajo".

Respecto de la transmisión de mensajes radiofónicos en lengua maya, casi la totalidad de los entrevistados están de acuerdo con ello (94 por ciento) "para que los que no hablan maya aprendan y escuchen, "porque es bonito y les gusta", "porque hay comunidades en donde no se habla español", "para que no se pierda la lengua", "porque él la habla", "para que los niños y jóvenes se interesen en aprender", "para que los que sólo hablan maya sepan las noticias", "para conservar las tradiciones, costumbres y raíces" y "para que se difunda la lengua y la cultura maya".

De acuerdo con nuestros datos, sabemos que aproximadamente 34 por ciento de la audiencia bajo la cobertura de "Radio Cadena..." es monolingüe castellano. Sin embargo, despunta a partir de los datos proporcionados por nuestros entrevistados que tienen y escuchan radio, que casi la totalidad de los entrevistados, incluyendo al segmento de quienes ni siquiera hablan la lengua maya, está de acuerdo con que se transmitan mensajes radiofónicos en dicha lengua. Al parecer, la distancia que implicaría el desconocimiento de la lengua maya entre la población mestiza no representa un rechazo frente a ella.

Unicamente 4 por ciento de la muestra expresó su desacuerdo con que se transmita en lengua maya a través de las emisoras de la región. Este dato es sumamente relevante, sobre todo si consideramos que, como ya se dijo antes, 34 por ciento habla sólo español. La información encontrada nos señala una actitud claramente positiva por parte del auditorio, sea indígena o mestizo, frente a lo "maya".

\section{Competencia en el cuadrante}

Una de las características que sobresalen de acuerdo con las preferencias de los radioescuchas que se encuentran dentro del área de cobertura de Radio Solidaridad, es la tendencia a seleccionar emisoras que contemplen música tropical o "guapachosa" en su programación. Las estaciones de radio preferidas por quienes cuentan con un aparato radiofónico y acostumbran escuchar la radio de manera cotidiana son:
a) Candela Tropicalísima (22 por ciento)
b) Radio Solidaridad (16 por ciento)
c) La Comadre (15 por ciento)
d) XEME Valladolid (11 por ciento)
e) La Poderosa (11 por ciento) 
Así, 75 por ciento de las preferencias de los entrevistados se concentra en estas cinco emisoras (Gráfica 6).

El resto de las estaciones referidas fueron: Extasis, La Rancherita, Radio Turquesa, Digital 99.3, Tu Nueva Barracuda, Juvenil FM, La Voz de los Mayas y Radio Universidad. Otras menciones fueron: Estéreo Maya, Radio 1450, Mix FM, Radio Lobo y Radio Fórmula.

\section{GRÁFICA 6 \\ Preferencias por emisora}

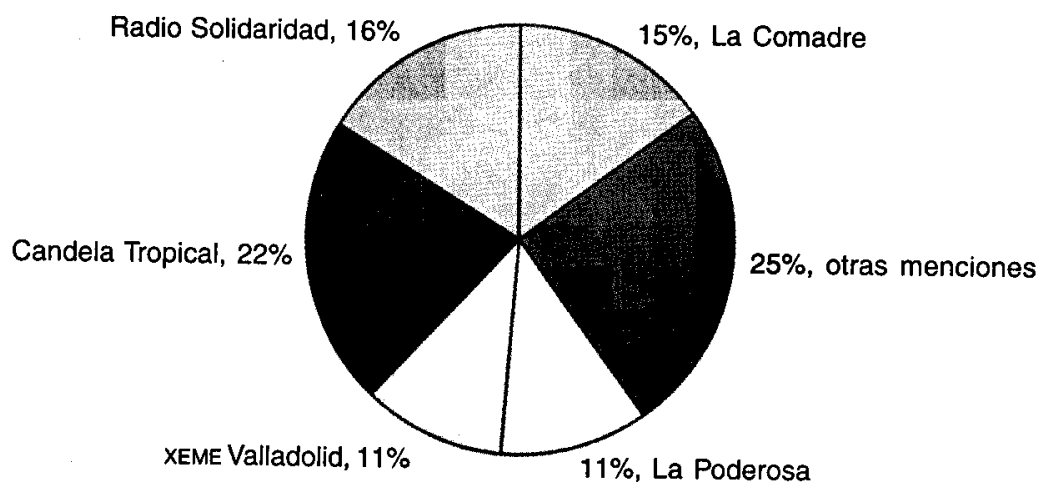

En términos de la variable sexo, las preferencias sufren una ligera modificación. Si bien, ambos recuerdan en primer lugar a la emisora Candela Tropicalísima (mujeres 12 por ciento, hombres 10 por ciento), la población femenina le concede el segundo lugar a La Comadre ( 9 por ciento) mientras que los hombres se lo otorgan a Radio Solidaridad ( 9 por ciento).

Por segmentos etarios, la muestra evidencia un comportamiento diferenciado. Encontramos que los más jóvenes escuchan en primer lugar Candela Tropicalísima, mientras que el segundo sitio lo comparten La Comadre y XEME Valladolid; los entrevistados de 25 a 34 años, señalan a Candela Tropicalísima y Radio Solidaridad; los de 35 a 44 años indicaron a La Comadre en primer lugar y a Radio Solidaridad en segundo; y los mayores de 45 años citaron a Radio Solidaridad en primer sitio seguida de Candela. Es posible deducir que a mayor edad se incrementa la preferencia por Radio Solidaridad y que ésta se encuentra determinada por los varones. 
De acuerdo con la variable lengua, los entrevistados monolingües castellano dijeron escuchar Candela Tropicalísima y La Comadre, respectivamente; los monolingües indigenas mencionaron a La Poderosa y Radio Solidaridad; y los bilingües citaron a Radio Solidaridad y Candela Tropicalísima.

De los entrevistados que escuchan de manera cotidiana alguna de las emisoras que transmiten en la región, la mitad de los mismos han oído alguna estación que habla de la cultura maya (50 por ciento). Tres aspectos se destacan en torno a la identificación por parte de los radioescuchas a propósito del nombre de la emisora que transmite mensajes en torno a la cultura maya: El primero, alude a la limitada "recordación" por parte de la audiencia del nombre de las estaciones de radio en las que podrían haber escuchado algún tópico relacionado con la cultura maya (62 por ciento). El segundo indica que Radio Solidaridad (19 por ciento) es la emisora más recordada. El resto de las menciones son: La Voz de los Mayas (8 por ciento), Radio Turquesa ( 3 por ciento), Radio Universidad ( 2 por ciento), La Comadre ( 2 por ciento) y Radio Cadena en Lengua Maya (1 por ciento). El tercero muestra la limitada identificación por parte de los entrevistados respecto de la "Radio Cadena en Lengua Maya" en este contexto.

Más de la mitad de los entrevistados que tienen y escuchan radio, han oído alguna vez programas o anuncios en lengua maya ( 55 por ciento). Es interesante advertir que, de alguna u otra manera, ya sea en anuncios, invitaciones o programación específica, la audiencia está expuesta a esta lengua; es decir, la transmisión de mensajes radiofónicos en maya no es ajena a la exposición cotidiana de los entrevistados quienes, aunque carezcan de información precisa, distinguen a la lengua maya como "cercana" a sus actividades.

\section{Análisis de los radioescuchas de la "Radio Cadena en Lengua Maya"}

Nivel de "escucha"

Los datos nos muestran que más de la mitad de la audiencia consultada que tiene y escucha radio, sean hombres o mujeres, sin importar la característica de la lengua, expresó haber escuchado en alguna ocasión Radio Solidaridad (65 por ciento) (Gráfica 7). En este sentido, habría que destacar que pese a la fuerte competencia del resto de las emisoras que transmiten en esta región, esta emisora aparece, de manera evidente, dentro de las preferencias de la audiencia. 
Si analizamos cada una de las rutas investigadas de manera independiente, resulta que los radioescuchas que habitan al oeste, suroeste y sur de Mérida, es decir, hasta Tetiz, Halachó y Santa Elena, son quienes escuchan en mayor medida a Radio Solidaridad (ruta 2,91 por ciento). Las regiones que le siguen en cuanto a nivel de preferencia se localizan en la propia capital yucateca (ruta 1, 78 por ciento), así como en la franja que va de Mérida hasta Valladolid (ruta 3, 71 por ciento). La zona que abarca el norte y sur de Valladolid, es decir, de Sucila a Tixcacalcupul, es donde menos se prefiere escuchar Radio Solidaridad (ruta 4, 23 por ciento). Quizás en esta ruta, lo reconocido por la proximidad territorial - Valladolid — es lo que más se escucha o con lo que el público de esta zona se identifica.

\section{GRÁFICA 7}

Escucha Radio Solidaridad

(Se excluye a quienes no tienen radio o no la escuchan)

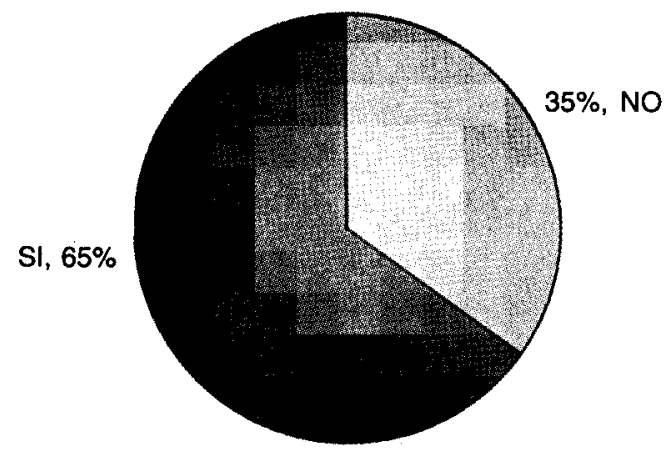

Respecto del segmento etario, resulta que tanto los jóvenes de 15 a 24 años como los mayores de 45 años que tienen y escuchan radio, han oído alguna vez Radio Solidaridad; pero, cabe subrayar que si consideramos las estaciones de radio que los entrevistados escuchan normalmente, Solidaridad aparece como tercera mención para estos jóvenes mientras que para los mayores de 45 representa la primera.

Como ya se anticipó, "Radio Cadena..." inició sus transmisiones hace menos de dos años a través de la frecuencia de Radio Solidaridad, en horario matutino, destinada principalmente a las personas que habitan en el campo. Pese a ello, el nivel de "escucha" que alcanza esta barra programática en la actualidad entre quienes tienen y escuchan radio ( 30 por ciento) es prometedor si consideramos el breve periodo que "Radio Cadena..." posee dentro del cuadrante (Gráfica 8). 
De nuevo, si consideramos cada ruta de manera independiente, se observa que la zona que se localiza entre Mérida y Valladolid es donde más se escucha "Radio Cadena..." (ruta 3, 47 por ciento), seguida de la región oeste, suroeste y sur de Mérida (ruta 2, 40 por ciento) y de la que cubre la capital yucateca (ruta 1, 31 por ciento). Al parecer, en las poblaciones que se encuentran al norte y sur de Valladolid es donde menos se escucha "Radio Cadena..." (ruta 4, 7 por ciento).

\section{GRÁFICA 8 \\ Escucha Radio Cadena}

(Se excluye a quienes no tienen radio o no la escuchan)

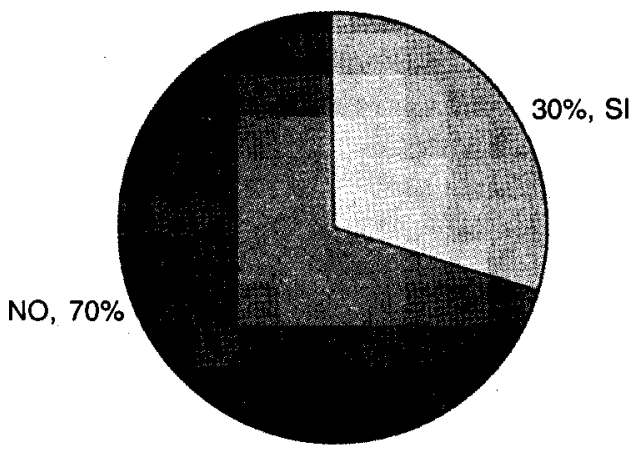

En cuanto a la variable sexo, se encontró que el sector masculino escucha "Radio Cadena..." en mayor medida que las mujeres, pese a ello, la diferencia entre ambos es mínima. Respecto de la edad, los mayores de 45 años son quienes escuchan en mayor proporción este espacio radiofónico, en contraparte, los más jóvenes son quienes menos lo oyen. En términos de la variable lengua, quienes menos escuchan la "Radio Cadena..." son los monolingües castellano, mientras que los monolingües indígenas como los bilingües reportaron haberla escuchado en alguna ocasión.

Sobre la barra "Radio Cadena...", se indagó por los tres programas radiofónicos que la integran, a saber, "El duende maya" (Arux K'at), "El despertar de los mayas" (U Yahal Mayao'ob) y "Nuestra vida" (K-Kuxtalil). De ellos, el más mencionado por los entrevistados que tienen radio y escuchan esta barra fue "El despertar..." (29 por ciento), mientras que "Nuestra vida", programa destinado a la audiencia femenina, obtuvo el menor porcentaje de los tres (17 por ciento). 
Se percibe que los tres programas son escuchados en mayor proporción por los hombres aunque ésta prevalencia no es significativa; además, quienes reportan una escucha más frecuente son los mayores de 45 años, por el contrario, quienes confiesan un hábito menos reiterado son los más jóvenes. Respecto de la lengua, los monolingües castellano son quienes menos sintonizan esta oferta programática, mientras que los monolingües indigenas y bilingües muestran mayor nivel de escucha de dichos programas.

De acuerdo con los datos, la audiencia de "Radio Cadena..." que cuenta con al menos un aparato radiofónico y suele escuchar radio cotidianamente, carece de información clara o no percibe como posible participar de manera activa en esta propuesta radiofónica por medio de cartas. Sólo 13 por ciento de los entrevistados ha hecho llegar sus inquietudes o sugerencias a la emisora vía postal.

\section{Preferencias y discrepancias}

70 por ciento de los entrevistados que escuchan "Radio Cadena...", indicaron cuatro razones positivas por las que sintonizan su señal en el cuadrante: "porque hablan en maya", "porque hablan de la historia de los pueblos", además de "las noticias" y "la música que transmiten". Como se constata, estas razones se relacionan con elementos que de alguna manera podrían conformar la "identidad maya": la lengua, la historia y las noticias de la región.

Del total de radioescuchas de "Radio Cadena...", únicamente 37 de ellos externaron claramente alguna discrepancia con dicha propuesta: "que pasen comerciales", "las noticias de la región", "el himno nacional en maya"y "que no se transmita música de moda", fueron las menciones más recurrentes.

Gran parte de nuestros entrevistados que escuchan "Radio Cadena..." perciben diferencias entre este espacio radiofónico y las otras emisoras que se escuchan en la zona (89 por ciento) ya que, según su opinión, en las otras emisoras "no hablan maya", "no pasan esos programas", "no hablan sobre la cultura maya", "no trasmiten música maya" o "no transmiten noticias sobre las comunidades mayas". Aquellos que no encuentran diferencias entre "Radio Cadena..." y el resto de las emisoras (11 por ciento), aseguran que "todas las radios hablan igual" o "ambas son igual de interesantes".

Por otro lado, poco más de la mitad de los entrevistados (51 por ciento), aseguraron que esta emisora había transmitido alguna vez consejos útiles que les sirvieron para solucionar problemas propios o de sus familiares, por ejemplo, consejos sobre salud y sobre el campo. 
La música que les gustaría oir a los radioescuchas de "Radio Cadena..." a través de su señal pertenece, en primer lugar, al género "balada o romántica" (20 por ciento), seguida de la música ranchera (18 por ciento), la jarana (16 por ciento) y la cumbia (16 por ciento). En cuanto a los temas que les gustaría que fueran transmitidos por la emisora se refieren a orientación y consejos en general (22 por ciento), agricultura (11 por ciento), cultura maya ( 9 por ciento), noticias de la región ( 9 por ciento), alimentación ( 6 por ciento) y problemas de población ( 5 por ciento).

\section{Conclusiones}

Los datos permiten mostrar algunos de los atributos del público receptor de "Radio Cadena en Lengua Maya". De acuerdo con la variable sexo, el perfil aproximado del radioescucha señala que son ligeramente más del sexo masculino ( 56 por ciento) que del femenino (44 por ciento). En cuanto a la edad, la mayoría tienen más de 45 años (43 por ciento) y la minoría posee de 15 a 24 (14 por ciento). Respecto de la lengua, lo más notable es la distancia entre los monolingües castellano y la oferta programática de "Radio Cadena...", ya que su preferencia resulta muy poco representativa. Por el contrario, los sectores bilingües y monolingües indígenas presentan un alto nivel de acercamiento a la "Radio Cadena...". Podemos concluir que el radioescucha de esta emisora proviene en mayor medida del sector masculino adulto, bilingüe o monolingüe indígena.

Los temas demandados a este espacio radiofónico se refieren por un lado, a la cultura maya (historia, lengua, música y noticias de la región) y, por otro, al reclamo de información que los apoye o ayude en la resolución de problemas de la vida cotidiana (orientación y consejos, la agricultura, alimentación y problemas de población). Así, se denota interés tanto en los aspectos que le dan sentido y explican sus vidas, como en aquellas temáticas cotidianas que posibilitan su existencia y los proyectan a futuro.

En este sentido, el espacio radiofónico denominado "Radio Cadena en Lengua Maya" comenzó sus transmisiones en junio de 1997; pese a ello, se advierte que 30 por ciento de la muestra total mencionó haber escuchado alguno de los programas que se difunden en dicha barra. Esta cifra se nos revela como promisoria.

$\mathrm{Si}$ bien aparece como contradictorio el porcentaje de quienes escuchan "Radio Cadena..." (30 por ciento) frente a quienes prefieren el horario de su emisión (11 por ciento), creemos que no se trata de una escucha cotidiana sino ocasional. Conjeturamos que elementos como las redes familiares o amicales aportan 
información a los radioescuchas respecto de la existencia de esta barra, posibilitando así, al menos, una sintonía eventual. Padres, amigos o compañeros de trabajo se desplazan por las distintas localidades de la zona de cobertura de Radio Solidaridad, llevando consigo gustos y conocimientos en tomo a la "Radio Cadena..." para después, al regresar a su lugar de origen, compartirlos con su familia o comunidad.

En cuanto al horario, sabemos que los horarios preferidos son el que va de las 12:00 a las 16:00, asi como cualquier hora del día. Sin embargo, encontramos que el 11 por ciento de la muestra total —en la que sobresalen los entrevistados de 45 a más años, monolingües indígenas y bilingües - escuchan radio muy temprano, de 5:00 a 6:00, es decir, durante la hora de transmisión de "Radio Cadena...".

Además, se advierte también que dentro de las preferencias o los gustos musicales de los entrevistados que escuchan la "Radio Cadena..." se destacan las menciones sobre la música tropical o "guapachosa", o bien, la "balada y romántica". Con base en lo anterior, podríamos explicar la sintonía itinerante por parte de los radioescuchas de "Radio Cadena..." en la medida en que dicha barra no contempla en su programación este tipo de oferta musical.

Asimismo, se observa que los elementos que parecen conformar la "identidad maya" aluden de manera directa a la historia, la lengua y las noticias de la región. Tales rasgos son los referidos con mayor recurrencia cuando se inquiere a los radioescuchas sobre los motivos por los cuales sintoniza "Radio Cadena...". Es probable que, a partir de este tipo de mensajes, el público se sienta interpelado y convocado, puesto que les estarían hablando de lo que sienten "propio" y "cercano" a su realidad como mayas.

Tal vez podríamos pensar a la "identidad indígena" como una especie de entramado dinámico y cambiante en donde el "núcleo duro" del mismo sea la lengua maya. En tal sentido, se podría aseverar que dicho entramado filtra, retoma, recrea y recibe acervos, gustos y creencias pertenecientes a la llamada "cultura mestiza". El gusto, de parte del público entrevistado, por creaciones musicales de moda tales como la cumbia, balada, música romántica o ranchera, pero sin dejar de lado sus raíces como la jarana, dan cuenta de hábitos de consumo de carácter intercultural que no hacen sino evidenciar cómo los sectores indígenas se alejan cada vez más del "nicho antropológico" en donde eran confinados en el pasado para participar de manera activa en la construcción de su ser maya contemporáneo. 